\title{
Hydroxysteroid dehydrogenases in the ovine endometrium and trophoblast
}

\author{
P. F. Flood* and R. Ghazi $\dagger$ \\ Department of Anatomy, University of Bristol, Park Row, \\ Bristol BS1 5LS, U.K.
}

\begin{abstract}
Summary. A histochemically demonstrable $3 \beta$-hydroxysteroid dehydrogenase appears in the uterine epithelium of the pregnant ewe on Day 12 and persists until after parturition. It is either very weak or absent in the non-pregnant ewe. A similar enzyme can just be seen in the trophoblast on Day 18 , increases in strength until Day 33 and persists to term. The appearance of the endometrial enzyme coincides with events associated with maternal recognition of pregnancy.
\end{abstract}

\section{Introduction}

A wide variety of hydroxysteroid dehydrogenases (HSDs) have been demonstrated histochemically in steroidogenic tissues and target organs, including the placenta (see Baillie, Ferguson \& Hart, 1966). The 12-day pig blastocyst possesses the ability to form oestrogens (Perry, Heap \& Amoroso, 1973) and histochemically demonstrable $3 \beta$ - and 17 $\beta$-HSDs. Further, the development of a 17ß-HSD in the uterine epithelium adjacent to the blastocyst on Day 15 (Flood, 1974) fits well with maternal recognition of pregnancy in this species. A $3 \beta-H S D$ is also present in the equine trophoblast by Day 13 (Flood \& Marrable, 1975) but the 17 $\beta$-HSD does not appear in the uterine epithelium until about 20 days gestation (P. F. Flood, unpublished observations). Luteal life is extended in the mare if an embryo is allowed to remain in the uterus until Day 15 (Hershman \& Douglas, 1979) and there is considerable evidence of steroid production by equine embryos prior to the time at which luteal regression would occur in the non-pregnant female (Hershman, Burns \& Douglas, 1977; Flood, Betteridge \& Irvine, 1979; Zavy, Mayer, Vernon, Bazer \& Sharp, 1979).

Because of the apparent relationship between the development of trophoblastic and endometrial HSDs and maternal recognition of pregnancy, and because of the known presence of HSDs in the sheep placenta (Ferguson \& Christie, 1967), the sheep was investigated in more detail. Although the paper is primarily concerned with early pregnancy, available data on the remainder of gestation are included for comparison and completeness.

\section{Materials and Methods}

Tissues were collected from 34 pregnant, 17 non-pregnant and 2 parturient ewes. All stages of gestation were represented but more animals were examined in the critical early stages (Text-fig. 1). Material from 16 ewes in late and mid-gestation was collected from animals of unknown

* Present address: Department of Veterinary Anatomy, Western College of Veterinary Medicine, University of Saskatchewan, Saskatoon, Saskatchewan, Canada, S7N OWO.

$\dagger$ Present address: Department of Animal Biology, School of Veterinary Medicine, Shiraz University, Shiraz, P.O. Box 257, Iran. 
history at a slaughterhouse; their gestational ages were estimated from data reviewed by Evans \& Sack (1973). The remaining pregnant ewes were maintained at pasture with a vasectomized ram until oestrus had been observed at least once and then mated with a fertile male (day of first mating $=$ Day 0). Clun, Welsh Mountain, Dorset Horn and Finnish Landrace sheep were used. One Finnish Landrace ewe was killed $\frac{1}{2} \mathrm{~h}$ post partum and another at $15 \mathrm{~h}$ post partum. Nine of the non-pregnant uteri were collected from the slaughterhouse: 5 during anoestrus and 4 at unknown stages of the cycle. Another 7 animals were found to be non-pregnant when killed on Days 3, 11 (2), 12, 13 (2) and 15 of the oestrous cycle. A remaining ewe was mated to a vasectomized male and killed on Day 14.

In non-pregnant uteri and those less than 20 days pregnant, segments about $3 \mathrm{~cm}$ long were excised from the base of each horn and from the junction of the middle and ovarian thirds. These were frozen in liquid nitrogen to preserve the topographical relationships between the trophoblast and the endometrium. Blocks were then sawn for transverse sectioning. At later stages the uterus was dissected to obtain appropriate tissues.

Frozen sections $(10 \mu \mathrm{m})$ were stained for the presence of HSDs by a well established method that has been fully discussed by Baillie et al. (1966). The sections were allowed to dry in air at room temperature for 5-10 min, then stored overnight in sealed plastic containers at $-15^{\circ} \mathrm{C}$. They were then rinsed briefly in phosphate buffer $(0.05 \mathrm{M}, \mathrm{pH} 7)$ to remove soluble endogenous substrates and incubated in Columbia jars at $37^{\circ} \mathrm{C}$ for $1 \mathrm{~h} \mathrm{in} 10 \mathrm{ml}$ of medium containing phosphate buffer $(0.05 \mathrm{M}, \mathrm{pH} 7)$, nitro-blue tetrazolium $(0.1 \mathrm{mg} / \mathrm{ml}), \mathrm{NAD}^{+}(0.25 \mathrm{mg} / \mathrm{ml})$, NADP $^{+}(0.25 \mathrm{mg} / \mathrm{ml})$ and the substrate $(0.15 \mathrm{mg} / \mathrm{ml})$. Each substrate was dissolved in $1 \mathrm{ml}$ dimethylformamide before addition to $9 \mathrm{ml}$ of the aqueous constituents. The following substrates were used; an abbreviation indicating the position of the active hydroxyl group is given in parentheses for some: androsterone $(\alpha-3 \alpha), 3 \alpha$-hydroxy-5 $\beta$-androstan-17-one

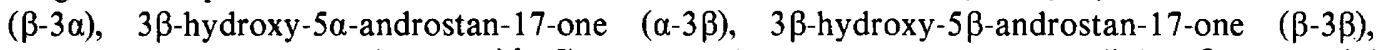
dehydroepiandrosterone (DHA, $\Delta^{5}-3 \beta$ ), pregnenolone, testosterone, oestradiol $17 \beta$, oestradiol $17 \alpha$, cortisol, $3 \alpha$-hydroxy-5 $\beta$-pregnan-20-one, $3 \beta$-hydroxy-5 $\alpha$-pregnan-20-one and $3 \beta$-hydroxy$5 \alpha$-pregnan-20-one. The slides were examined by conventional and phase-contrast optics and compared with adjacent sections stained in haematoxylin and eosin. The intensity of staining was scored on an arbitrary scale from 1 to 5 : a score of 1 was assigned to a weak but unequivocal response and 5 to the kind of intense blue-black staining seen with $\beta-3 \beta$ in the ovine corpus luteum and parts of the adrenal cortex. A mid-blue like that seen in the trophoblast of the horse or pig with $\Delta^{5}-3 \beta$ was scored 3 and doubtful reactions were shown as 0.5 . All scoring was done by the same observer using the guidelines indicated above. At least 2 samples were taken from each placenta and 4 from those before 20 days gestation. Normally, only one section from each block was incubated with each medium but when duplicates were used, they behaved identically unless they were obviously damaged.

\section{Results}

Histochemical evidence of the presence of HSDs was confined to the uterine epithelium and trophoblast. The most vigorous activity was seen with $\beta-3 \beta$ and $\alpha-3 \beta$ substrates. Responses were seen with $\Delta^{5}-3 \beta$ substrates and $\alpha-3 \alpha$ but these were irregular, weak and often equivocal. The observation of Ferguson \& Christie (1967) that cortisol was metabolized by the uterine epithelium in later gestation was confirmed. Testosterone, oestradiol-17 $\beta$ and oestradiol-17 $\alpha$ all failed to react.

Detailed results for the more reactive substrates are shown in Text-fig. 1. The most notable points were (1) that $\beta$-3 $\beta$ HSD activity appeared in the uterine epithelium on Day 12 , peaked on Day 18 and persisted in the intercotyledonary areas until at least $15 \mathrm{~h}$ post partum (Plate 1); and 
PLATE 1

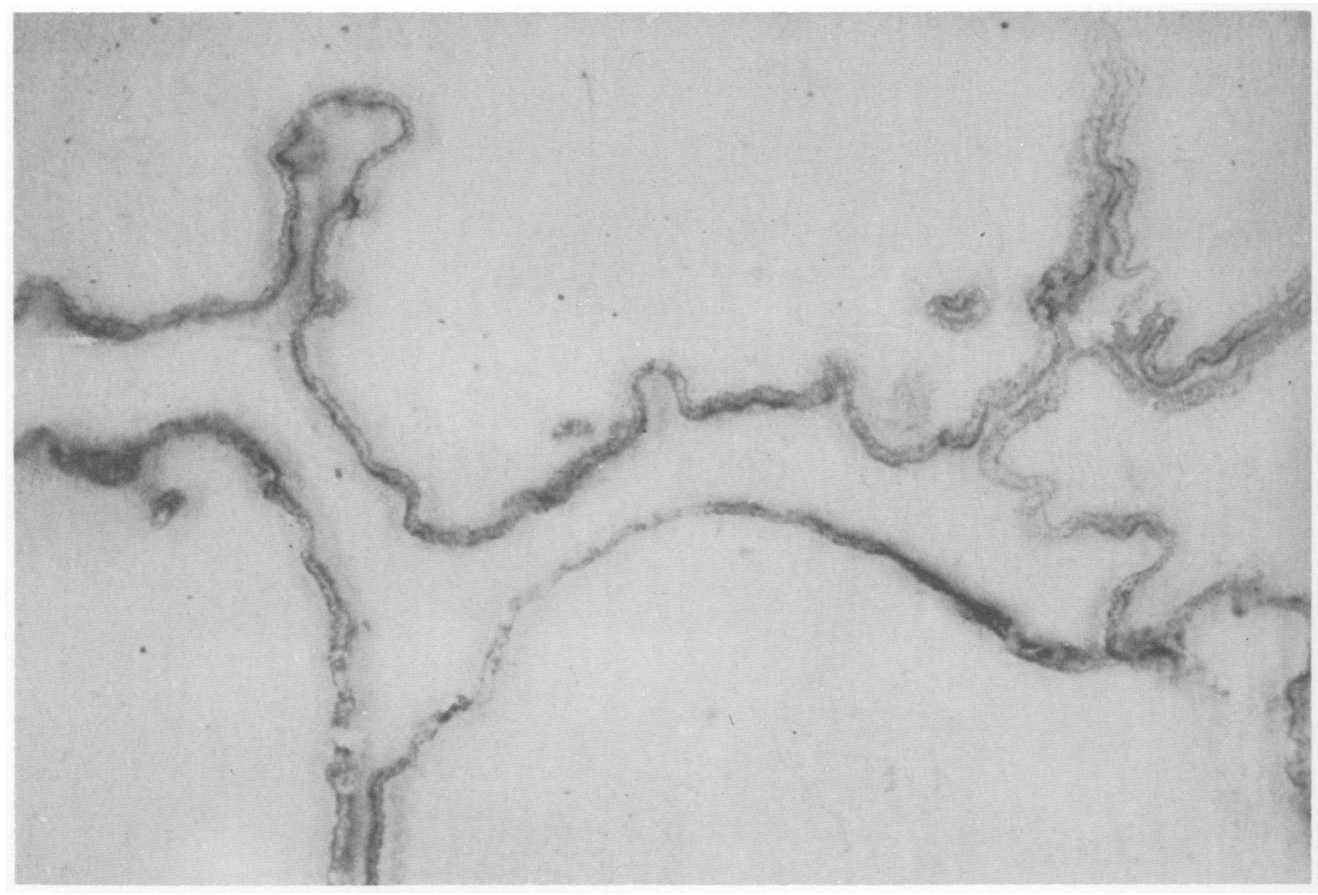

Histochemical evidence of $3 \beta$-hydroxysteroid dehydrogenase in the uterine epithelium of the sheep on Day 16 of gestation. Substrate: $5 \beta$-androstan-3 $\beta$-ol-17-one. Transverse section, $\times 40$. 


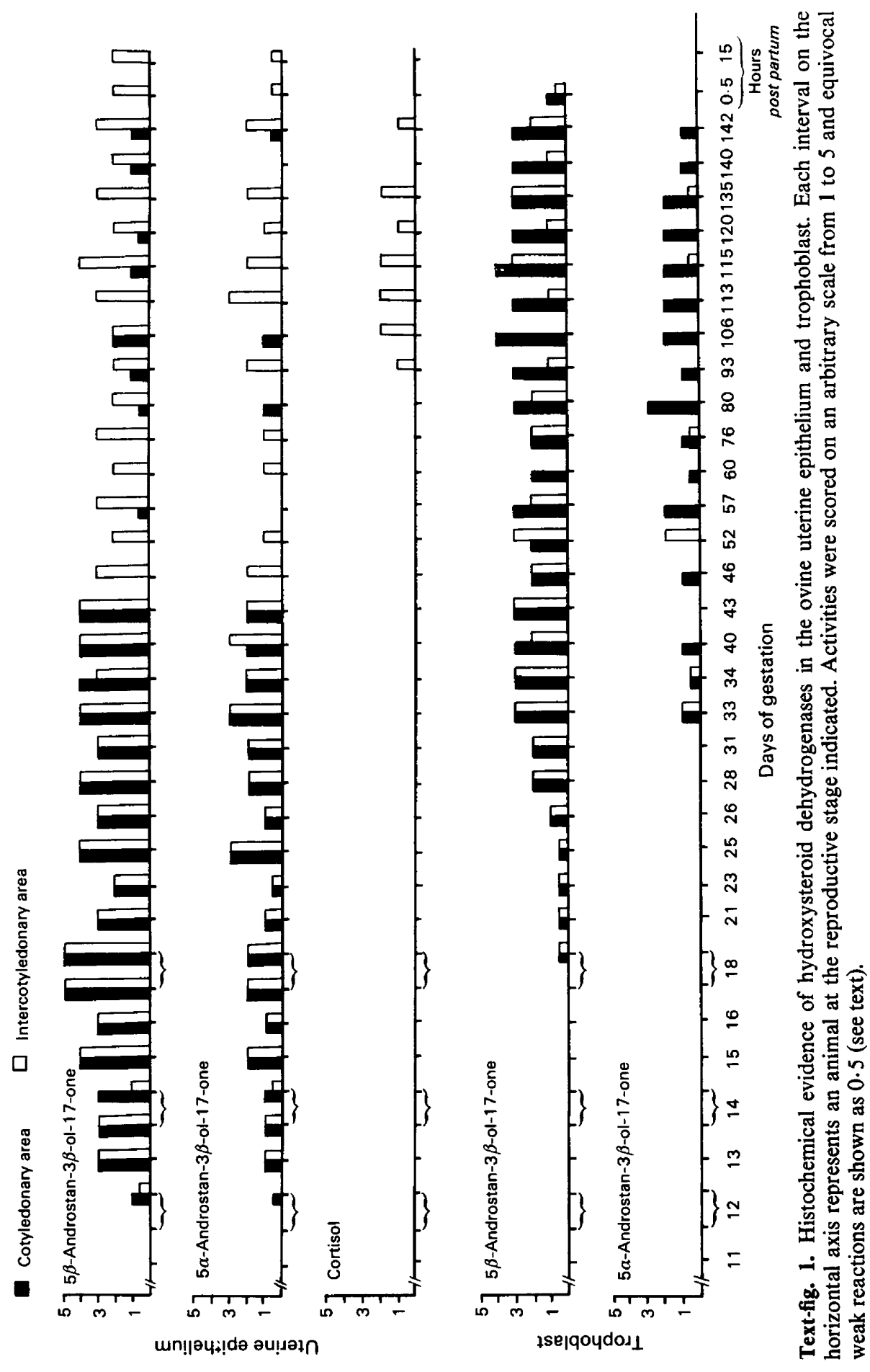


(2) that $\beta-3 \beta$ activity appeared in the trophoblast on Day 18 , increased until Day 33 and remained high thereafter, at least in the cotyledonary trophoblast; staining of the intercotyledonary trophoblast was variable. Reactions with $\alpha-3 \beta$ were less intense but seemed to follow a pattern similar to those seen with $\beta-3 \beta$. This is clear in the uterine epithelium but less so in the trophoblast because of the very gradual increase in $\beta-3 \beta$ activity.

Although strong reactions were obtained with androstanes, the only staining observed in these tissues with the corresponding pregnanes was at the lowest detectable level in the uterine epithelium on Day 18 with $3 \beta$-hydroxy-5 $\alpha$-pregnan-20-one.

No reactions were found in the uterine epithelium during anoestrus or in the mated animals found to be non-pregnant at slaughter. Two of the 4 uteri collected from cyclic animals at the slaughterhouse and the uterus of the ewe mated to a vasectomized ram (Day 14) showed just detectable reactions in the luminal epithelium with $\beta-3 \beta$ and $\alpha-3 \beta$.

Substrate-free controls were uniformly negative and sections incubated with $\mathrm{NADH}_{2}$ or $\mathrm{NADP}_{2}$ stained strongly, indicating adequate levels of the diaphorases necessary for the reduction of nitro-blue tetrazolium.

\section{Discussion}

The information derived from this study is in good agreement with the findings of Ferguson \& Christie (1967) and extends them to the non-pregnant animal and into the critical early stages of gestation. However, some ambiguity exists because these authors use the terms 'cytotrophoblast' and 'syncytiotrophoblast' which are not readily applicable to the epitheliochorial placenta of the sheep (see Bjorkman, 1970).

The appearance of histochemically detectable concentrations of $\beta-3 \beta$ HSD in the uterine epithelium by Day 12 (Plate 1) precedes the pontamine blue reaction occurring in the sheep on Day 15 (Boshier, 1970) and possibly precedes the increased apical acid phosphatase activity seen by Boshier (1969) for the earliest pregnancies collected on Day 14. It coincides with the beginning of blastocyst elongation (Rowson \& Moor, 1966)—of the two Day-12 blastocysts recovered in this study, one was roughly spherical and $5 \mathrm{~mm}$ in diameter while the other was filamentous and was cut during the preparation of the uterus. A positive histochemical response was only seen in the latter uterus. Day 12 is also the last day on which an embryo may be allowed to remain in the uterus if the cycle is not to be prolonged (Moor \& Rowson, 1966a; Edey, 1967) and the last day on which an embryo may be transferred to the uterus with a reasonable chance of achieving pregnancy (Moor \& Rowson, 1966b). The stimulus leading to the development of strong $\beta-3 \beta$ HSD activity in the endometrium would seem to be the embryo itself and not the act of mating or the presence of semen because non-pregnant but mated females gave negative results and the ewe killed 14 days after mating with a vasectomized ram only reacted at the limit of detectability. Similarly, 2 of the 4 luteal-phase ewes of unknown history showed only very slight reactions that were very different from those of their pregnant counterparts.

The nature of the stimulus is unknown although possibilities include the anti-luteolytic hormone "trophoblastin" reported by Martal, Lacroix, Loudes, Saunier \& Wintenberger-Torrès (1979), the pregnancy specific antigens of Cerini, Findlay \& Lawson (1976), the anti-luteolysin from the pregnant uterus (Mapletoft, Lapin \& Ginther, 1976), prostaglandins of embryonic origin as demonstrated in cattle (Shemesh, Milaguir, Ayalon \& Hansel, 1979) and sheep (J. H. Hyland, personal communication) and embryonic steroids. Gadsby, Heap \& Burton (1980) noted extensive metabolism of both androstenedione by a Day 15 sheep blastocyst but about $95 \%$ of this remained in the neutral fraction.

Initially, it was felt that the high histochemical activities seen with $5 \alpha$ - and $5 \beta$-reduced steroids might be fortuitous and have limited physiological significance; however, a similar, 
histochemically demonstrable $3 \beta$-HSD in rat Leydig cells metabolizes $\alpha-3 \beta$ and $\beta-3 \beta$ very much more rapidly than other steroids at a time when 5 -saturated $\mathrm{C}_{19}$ steroids are present in the testis (Wiebe, 1976). Similar compounds may be present in the sheep blastocyst where they could form substrates for the endometrial HSD, stimulate its formation, or both. Androgens are abundant in the equine pre-attachment embryo (Flood et al., 1979) and 5-saturated androgens are produced by the bovine conceptus at 14 days gestation (Chenault \& Hruska, 1979). Later in gestation the fetal liver is a potential substrate source since over half the androstenedione it metabolizes can be accounted for as $\alpha-3 \beta$ and $\beta-3 \beta$ (Anderson, Pierrepoint, Turnbull \& Griffiths, 1973).

Since $3 \beta$-HSD cannot be localized in the trophoblast before Day 18 , it seems possible that the maturing trophoblast acquires pathways that previously predominated in the endometrium. These findings augment those of Marcus, Ainsworth \& Lucis (1979) who have demonstrated that dispersed chorionic cells from Day-21 pregnant sheep can synthesise cholesterol from labelled acetate and accumulate progesterone in culture. Like Gadsby (1980), these authors feel that progesterone is further metabolized in the chorion and this fits well with the presence of a $3 \beta$-HSD.

Insufficient animals were examined at the end of gestation to decide whether the HSDs examined changed consistently before parturition. However, the apparent marked decline in $3 \beta$-HSD in the cotyledonary trophoblast between Day 142 and $\frac{1}{2} \mathrm{~h}$ post partum suggests such changes may exist.

\section{References}

Anderson, A.B.M., Pierrepoint, C.G., Turnbull, A.C. \& Griffiths, K. (1973) Steroid investigations in the developing sheep foetus. In The Endocrinology of Pregnancy and Parturition, pp. 23-39. Ed. C. G. Pierrepoint. Alpha Omega Alpha, Cardiff.

Baillie, A.H., Ferguson, M.M. \& Hart, D. McK. (1966) Developments in Steroid Histochemistry. Academic Press, London.

Bjorkman, N. (1970) An Atlas of Placental Fine Structure. Baillière, Tindall \& Cassell, London.

Boshier, D.P. (1969) A histological and histochemical examination of implantation and early placentome formation in sheep. J. Reprod. Fert. 19, 51-61.

Boshier, D.P. (1970) Pontamine blue reaction in pregnant sheep uteri. J. Reprod. Fert. 22, 595-596.

Cerini, M., Findlay, J.K. \& Lawson, R.A.S. (1976) Pregnancy-specific antigens in the sheep: application to the diagnosis of pregnancy. $J$. Reprod. Fert. 46, $65-69$.

Chenault, J.R. \& Hruska, R.L. (1979) Steroid $\Delta^{4}$ $5 \beta$-reductase in bovine preattached conceptus. $J$. Anim. Sci. 49, Suppl. 1, Abstr. 355, p. 285.

Edey, T.N. (1967) Early embryonic death and subsequent cycle length in the ewe. J. Reprod. Fert. 13, 437-443.

Evans, H.E. \& Sack, W.O. (1973) Prenatal development of domestic and laboratory mammals: growth curves, external features and selected references. Anat. Histol. Embryol. 2, 11-45.

Ferguson, M.M. \& Christie, G.A. (1967) Distribution of hydroxysteroid dehydrogenases in the placentae and foetal membranes of various mammals. $J$. Endocr. 38, 291-306. early pig conceptus and in the related endometrium. J. Endocr. 63, 413-414.

Flood, P.F. \& Marrable, A.W. (1975) A histochemical study of steroid metabolism in the equine fetus and placenta. J. Reprod. Fert., Suppl. 23, 569-573.

Flood, P.F., Betteridge, K.J. \& Irvine, D.S. (1979) Oestrogens and androgens in blastocoelic fluid and cultures of cells from equine conceptuses of 10-22 days gestation. J. Reprod. Fert., Suppl. 27, 413420.

Gadsby, J.E., Heap, R.B. \& Burton, R.D. (1980) Oestrogen production by blastocyst and early embryonic tissue of various species. J. Reprod. Fert. 60, 409-417.

Hershman, L. \& Douglas, R.H. (1979) The critical period for maternal recognition of pregnancy in mares. J. Reprod. Fert., Suppl. 27, 395-401.

Hershman, L., Burns, P.J. \& Douglas, R.H. (1977) Effects of non-surgical blastocyst removal on interovulatory interval in mares and progesterone production in vitro by the equine blastocyst. J. Anim. Sci. 45, Suppl. 1, 169, Abstr.

Mapletoft, R.J., Lapin, D.R. \& Ginther, O.J. (1976) The ovarian artery as the final component of the local luteotrophic pathway between a gravid uterine horn and ovary in ewes. Biol. Reprod. 15, 414-421.

Marcus, G.L., Ainsworth, L. \& Lucis, R. (1979) Cholesterol biosynthesis and progesterone production by chorionic cells of the early sheep conceptus in vitro. Steroids 34, 295-303.

Martal, J., Lacroix, M.-C., Loudes, C., Saunier, M. \& Wintenberger-Torrès, S. (1979) Trophoblastin, an antiluteolytic protein present in early pregnancy in

Flood, P.F. (1974) Steroid-metabolizing enzymes in the MEO. 
Moor, R.M. \& Rowson, L.E.A. (1966a) The corpus luteum of the sheep: effect of removal of embryos on luteal function. J. Endocr. 34, 497-502.

Moor, R.M. \& Rowson, L.E.A. (1966b) The corpus luteum of the sheep: functional relationships between embryo and corpus luteum. J. Endocr. 34, 233-239.

Perry, J.S., Heap, R.B. \& Amoroso, E.C. (1973) Steroid hormone production by pig blastocysts. Nature, Lond. 245: 45-47.

Rowson, L.E.A. \& Moor, R.M. (1966) The development of the sheep conceptus during the first fourteen days. J. Anat. 100, 777-785.
Shemesh, M., Milaguir, F., Ayalon, N. \& Hansel, W. (1979) Steroidogenesis and prostaglandin synthesis by cultured bovine blastocysts. J. Reprod. Fert. 56, 181-185.

Wiebe, J.B. (1976) Steroidogenesis in rat Leydig cells: changes in activity of 5-ane and 5-ene $3 \beta$-hydroxysteroid dehydrogenases during sexual maturation. Endocrinology 98, 505-513.

Zavy, M.T., Mayer, R.E., Vernon, M.W., Bazer, F.W., \& Sharp, D.C. (1979) An investigation of the uterine luminal environment of non-pregnant and pregnant pony mares. J. Reprod. Fert., Suppl. 27, 403-411.

Received 3 March 1980 